\title{
Burden and Psychological Well-being among Schizophrenia Patients' Caregivers
}

\section{Dr. Bakhtawar (M.B.B.S); Dr. Waseem Iqbal (M.B.B.S); Dr. Ruhma Farooqi (M.B.B.S)}

\begin{abstract}
:
There exists definite scarcity of studies seeking burden nd psychological well-being among caregivers and interfacing among them. This study therefore is aimed to investigate burden and psychological well-being among Schizophrenia patients' caregiver for this purpose, sample of 100 patients facing schizophrenia and caregivers of such patients was selected at random from patients admitted in female and male wards of psychiatric center, Karachi Pakistan as per exclusion and inclusion criteria selected and used the PGWI (Psychological General Well-being Index) and BAS (Burden Assessment Schedule).

Results of study identified that about 8 percent of caregivers reported that they were experiencing the moderate burden levels while caring for schizophrenia patients while older people felt relatively more burden $(\mathrm{r}=0.334)$ while spouses (po 0.0001). In addition results revealed that the psychological well-being is relatively lower among old age caregivers $(\mathrm{r}=0.44)$ and among the caregivers with higher in siblings and lower in education status $(\mathrm{p}=$ 0.002). Study identified strong negative relationship between psychological well-being and burden $(\mathrm{r}=-0.81)$ among caregivers, giving care to schizophrenia patients.

Study, therefore concluded that the care given to the patients of schizophrenia is depending on primary caregivers, therefore it is essential and important to plan necessary strategies and interventions in order to minimize and reducing the burden, resulted into improved psychological well-being.
\end{abstract}

Keywords: Schizophrenia, Psychological well-being, burden, caregivers. 


\section{Introduction}

Research studies have identified that the chronic and severe mental diseases like the schizophrenia have significant impact on the patients' caregivers and family members. Such mental diseases usually diminishing their capacity for social relationship while reducing the employment opportunities ${ }^{1,2}$. Advanced treatment methods and approaches are aiding large number of patients in improving and recovering significantly but many of these approaches and methods are continuously showing the deficits in different functional areas. Relatives and caregivers of patients are experiencing range of emotional changes i.e. from anger to guilt and from grief to loss. These caregivers, like the patients are feeling the stigmatized and isolated ${ }^{3,4}$. Caregivers are usually found themselves bound by the obligations of kinship, adopting certain responsibilities and duties, far excess of those responsibilities they might have if spending normal family roles and life at particular stage $^{5,6,7}$. Studies identified that the problems are exacerbated if this caregiving responsibility prolonged which usually last unit death of patient(s) and things would not improve with passage of time.

Caregivers further found that they have no other choice ${ }^{8}$, making these caregiving making it burdensome and it would be satisfactory and source of joy, rarely. The burden which caregivers are carrying and feeling is defined as the "existence of difficulties, problems and/or adverse events which affects lives of family members/caregivers of psychiatric patients" 9 . Different studies described and defined the burden differently but all definitions are sharing common underlying aspects and frame of reference. In Pakistan and India and other parts of subcontinent, contrary to the Western counterparts, caregivers are not excluded systematically from treatments of patients, and primary caregivers are taking an active part in mental healthcare, mainly due to the cultural and social requirements and bindings and also characterized with the inadequacy of facilities and physical infrastructure ${ }^{10}$. Family setup in subcontinent are usually involved in different roles and responsibilities related to care to the patients, recognized as prominent and major role players in decisions related to the patients specifically regarding disengagement and engagement from the process of treatment, providing everyday care, supervision of medication, and emotional and physical support to the patients and individuals ${ }^{11,12}$.

Burden to caregivers is having subjective and objective components ${ }^{13,14}$. Subjective components are relatively less and clinical factors are appeared in determining the extent of demographic and burden factors and their patterns. Coping and stress frameworks are considered helpful specifically for mental health professionals in order to develop in-depth understanding of range of adaptational responses, developed and given by the caregivers to caring stress for patients with mental illness ${ }^{15,16}$. This perspective is considered as responses of individuals to situation, perceived as taxing or situation which exceeds their abilities of contended with patients ${ }^{17}$.

Caring the people and patients with schizophrenia is considered as the chronic stress giver to caregivers and family members and coping with which involves continuous adjustment to the usual and frequent disruptions and crises in family life ${ }^{18}$. Due to having limited sources is further adding and compounding the issues and associated problems and resulted into the non-financial and financial hardships ${ }^{19}$. Caregivers, due to their caregiving roles are experiencing considerable stress and distress and therefore are vulnerable to the 
development of certain minor psychiatric issues and disorders for example including depression and anxiety.

Therefore the psychological well-being and burden that caregivers are experiencing and interface between these two aspects must be assessed in order to develop certain useful strategies that would care for caregivers.

Western Studies, though have intensively looked into this relationship but there is definite scarcity in

\section{Methodology}

Population of this study is based on the patients of schizophrenia and caregivers to these patients Pakistan and for this purpose the sample of 100 patients diagnosed with schizophrenia in Institute of Psychiatry in University of Karachi, Karachi and caregivers to these patients were selected at random from those admitted in female and psychiatric

\section{Criteria for Exclusion and Inclusion:}

This study included the $1^{\text {st }}$ degree relatives of patients i.e. the offspring, siblings of patients, or parents and/or spouses of schizophrenia patients as per $10^{\text {th }}$ revision of ICD (International Classification of Diseases) and were found involved in caring the

\section{Tools used in Study:}

\section{PSP (Patient's Socio-Demographic Performa):}

This performa was designed to collect information and developed record demographic information for example, gender, age, marital status, education, and area of residence of the patients and respondents. This performa also seeks information regarding the duration of illness and diagnosis of illness.

\section{CSP (Caregiver Socio-Demographic Performa):}

subcontinent in this area. Additionally, bearing these western studies, few of these studies investigated this relationship therefore this study is aimed to identify and evaluate the relationship between psychological wellbeing and the experienced burden while providing care to Schizophrenia patients.

center's male wards, Karachi, after taking informed consent from selected caregivers and patients. This study used purposive sampling therefore nonprobability sampling design was used, based on exclusion and inclusion criteria, summarized as under.

patients and/or living with them for at least last six months before assessment. This study excluded all the patients with other substance-induced disorder, or medical illness or other comorbid psychiatric disorder.

This performa is used to collect information and record required information regarding caregiver for example their relationship with different demographic aspects including "age", "gender", "duration of relationship", "duration of care", "educational status" and so on.

\section{BAS (Burden Assessment Schedule):}

This scale was actually developed by the RFS (Research Foundation of Schizophrenia), Channai, India in order to assess the burden on caregivers of 
patients with schizophrenia. Step-wise ethnographic method of exploration was used to develop this scale and to develop different contextual items, reflecting the opinion of caregivers about themselves instead the opinion of researchers. This scale was comprised of 40 different items, rated on 3-points scale and markets from 1 to 3 and some among these items were reverse coded. The score of scale in total varies from 40 to 120 and higher score shows that there is higher burden on caregiver. This scale was validated against FBS (Family Burden Schedule) by Pai \& Kanpur ${ }^{20}$. Correlation determined for this validation varied between 0.71 and 0.82 for almost 70 percent of items. The test-retest reliability of scale for 3 months period was determined as 0.91 , having coefficient value of 0.92 while determined inter-rater reliability of scale was $0.80^{21}$. This scale is used for this study mainly due to the fact that it was developed in sub-continent setting, aiding to develop in-depth understanding and interpreting burden while considering the cultural aspects and contexts.

\section{Methods:}

Models and methods used to describe the results and collected data include descriptive statistics while the results on continuous variables are measured through Mean \pm SD while the results of categorical variables and factors are summarized in percentage and number. 5\% level of significance is used to test and

\section{Results of Analysis:}

Table 1 below is showing the socio-demographic characteristics of selected sample and showing that about $45 \%$ of sample was from age group of 20 to 29 years while $35 \%$ from age group of 30 to 39 years. About 86 percent of patients were male while

\section{PGWBI (Psychological General Well- Being Index):}

This PGWBI is 22 items scale related to the HRQoL (Health Related Quality of Life) scale, providing the self-perceived health related well-being evaluation which is expressed exclusively by the summary/total score of scale. The original scale was comprised of 22 self-reported items which were rated on 6-point scale, assessing the respondents' general and psychological well-being in different health related quality of life dimensions and domains including vitality, general health, self-control, positive wellbeing, depressed mood, and anxiety. Each of these domains are defined through 3 to 5 items, while total score of all domains is summarized in order to provide the summary score, and maximum score of this scale is 110 which is representing the best achievable well-being.

measure the significance while parametric tests are used to identify the significance of parameters in study for example including ANOVA (Analysis of Variance), t-test, and Correlation coefficient is calculated in order to identify the relationship between these factors and variables.

remaining 14 percent were female patients. 20 percent of respondents were illiterate while overall education level of patients was low and about 72 percent of respondents were found unemployed. 
Table 1: Socio-demographic Aspects - Patient Sample

\begin{tabular}{lcc}
\hline Variables & \# of respondents (n=100) & \%age \\
\hline Age Groups: & 45 & $45.00 \%$ \\
$21---30$ Years & 35 & $35.00 \%$ \\
$31---40$ Years & 12 & $12.00 \%$ \\
$41---50$ Years & 8 & $8.00 \%$ \\
51 years and Above & & \\
Gender Groups: & 86 & $86.00 \%$ \\
Males & 14 & $14.00 \%$ \\
Females & & \\
Educational Status & 20 & $20.00 \%$ \\
Illiterate Person & 38 & $38.00 \%$ \\
Primary Level & 16 & $16.00 \%$ \\
Middle Level & 14 & $14.00 \%$ \\
Secondary Level & 12 & $12.00 \%$ \\
Graduation and Post-Graduation & & \\
Residential Area/Location & 68 & $68.00 \%$ \\
Rural Residential Area/Location & 32 & $32.00 \%$ \\
Urban Residential Area/Location & & \\
Status of Employment & 28 & $28.00 \%$ \\
Employed Respondents & 72 & $72.00 \%$ \\
\hline Unemployed Respondents & & \\
\hline
\end{tabular}

Table 2 similarly is summarizing the sociodemographic features of caregivers and it is identified that about 40 percent of caregivers were from oldest age group i.e. 50 years and above, followed by the second oldest group i.e. 40---49 years which contained 19 percent of respondents. 81 percent of total caregivers were male while 19 percent were female, and mostly (76\%) were employed. 
Table 2: Socio-demographic Aspects - Caregivers Sample

\begin{tabular}{|c|c|c|c|}
\hline Variables & \# of respondents $(\mathrm{n}=100)$ & \multicolumn{2}{|c|}{ \%age } \\
\hline & & \multicolumn{2}{|c|}{ Age Groups: } \\
\hline 21---30 Years & & 15 & $15.00 \%$ \\
\hline 31---40 Years & & 26 & $26.00 \%$ \\
\hline 41---50 Years & & 19 & $19.00 \%$ \\
\hline 51 years and Above & & 40 & $40.00 \%$ \\
\hline \multicolumn{4}{|l|}{ Gender Groups: } \\
\hline Males & & 81 & $81.00 \%$ \\
\hline Females & & 19 & $19.00 \%$ \\
\hline \multicolumn{4}{|l|}{ Educational Status } \\
\hline Illiterate Person & & 32 & $32.00 \%$ \\
\hline Primary Level & & 19 & $19.00 \%$ \\
\hline Middle Level & & 15 & $15.00 \%$ \\
\hline Secondary Level & & 15 & $15.00 \%$ \\
\hline Graduation and Post-Graduation & & 19 & $19.00 \%$ \\
\hline \multicolumn{4}{|l|}{ Residential Area/Location } \\
\hline Rural Residential Area/Location & & 69 & $69.00 \%$ \\
\hline Urban Residential Area/Location & & 31 & $31.00 \%$ \\
\hline \multicolumn{4}{|l|}{ Status of Employment } \\
\hline Employed Respondents & & 76 & $76.00 \%$ \\
\hline Unemployed Respondents & & 24 & $24.00 \%$ \\
\hline
\end{tabular}

Table 3 below is summarizing the caregivers' percent of caregivers were parents, while 36 percent, distribution and categorization with respect to their 19 percent and 6 percent were siblings, spouses and relations with the patients and found that about 39 children respectively.

Table 3: Caregivers' relations with Patients

\begin{tabular}{lcr}
\hline Relationship & \# of Caregivers (n=100) & \%age \\
\hline Parents (Father/Mother) & 39 & $39.00 \%$ \\
Spouses (Husband/Wife) & 19 & $19.00 \%$ \\
Siblings (Sister/Brother) & 36 & $36.00 \%$ \\
Others (Daughter/Son) & 6 & $6.00 \%$ \\
\hline
\end{tabular}

Table 4 below is showing the duration for which caregivers are caring for patients and it is identified that 70 percent of entire population is given and provided with care for less than 10 years, 61 percent 
were provided with care for less than 5 years and average duration of given care was $7.02 \pm 4.98$ years. Similarly, average/mean burden score among the caregivers was $69.28 \pm 11.87$ and results revealed that 78 percent of caregivers were experience the burden of moderate level while 22 percent of the caregivers were experiencing the severe level distress and burden.

\section{Table 4: Caregiving (Duration in Years)}

\begin{tabular}{lrr}
\hline Caregiving (Duration in Years) & \# of Caregivers (n=100) & \%age \\
\hline From 0 to 5 Years & 61 & $61.00 \%$ \\
From 6 to 10 Years & 9 & $9.00 \%$ \\
For more than 10 Years & 30 & $30.00 \%$ \\
\hline
\end{tabular}

Table 5 below is showing and summarizing the results of correlation between experienced distress and burden and socio-demographic factors of the caregivers and identified that there exists the significant positive relationship between age group of caregivers and the level of distress and burden they experienced i.e. $r=0.334$. Results also revealed that there exist no statistically significant difference between experienced level of burden/distress considering the educational status of caregivers as well as with respect to the residential area/location of caregivers.

Table 5 Relationship between Burden/Distress and Socio-Demographic Factors of Caregivers

\begin{tabular}{lll}
\hline Variables & BAS (Mean \pm SD) & Significance \\
\hline Age Groups: & $59.23 \pm 9.41$ & \\
$21---30$ Years & $65.27 \pm 11.43$ & $\mathrm{r}=0.334$ \\
$31---40$ Years & $76.31 \pm 12.88$ & $\mathrm{p}=0.05(\mathrm{~S})$ \\
$41---50$ Years & $69.79 \pm 09.28$ & \\
51 years and Above & & \\
Gender Groups: & $71.01 \pm 11.71$ & $\mathrm{t}=1.732$ \\
Males & $76.48 \pm 7.98$ & $\mathrm{p}=0.105$ (NS) \\
Females & & $\mathrm{p}=0.209$ (NS) \\
Educational Status & $75.29 \pm 11.14$ & \\
Illiterate Person & $71.65 \pm 07.31$ & \\
Primary Level & $71.22 \pm 12.19$ & \\
Middle Level & $73.45 \pm 11.87$ & \\
Secondary Level & $69.48 \pm 10.81$ & $\mathrm{t}=0.5182$ \\
Graduation and Post-Graduation & & $\mathrm{p}=0.712$ (NS) \\
Residential Area/Location & $75.31 \pm 11.11$ & \\
Rural Residential Area/Location & $71.09 \pm 10.91$ & \\
Urban Residential Area/Location &
\end{tabular}




\section{Status of Employment}

Employed Respondents

$68.44 \pm 11.85$

$\mathrm{t}=0.451$

Unemployed Respondents

$74.66 \pm 10.07$

$\mathrm{p}=0.872(\mathrm{NS})$

BAS (Burden Assessment Schedule);

Not Significant (NS)

Table 6 below is summarizing the burden and distress

distress is experienced by the parents while siblings distribution with respect to the relationship of reported the relatively low level of burden. The caregivers with patients, also the caregiving's mean duration. The distress and burden levels were found results identified significant positive correlation between duration for care and burden level (0.29).

highest among the spouses while second highest

Table 6: Correlation of Distress/Burden based on Relationship of Caregivers with Patients and Duration of Care in Years

\begin{tabular}{lll}
\hline Variables & BAS (Mean \pm SD) & Significance \\
\hline Relationship & & \\
Parents (Father/Mother) & $69.98 \pm 6.98$ & $\mathrm{p}<0.0001(\mathrm{~S})$ \\
Spouses (Husband/Wife) & $81.18 \pm 10.39$ & \\
Siblings (Sister/Brother) & $69.45 \pm 11.55$ & \\
Others (Daughter/Son) & $65.09 \pm 5.18$ & \\
Average Caregiving Duration in Years 07.22 \pm & & $\mathrm{r}=0.29, \mathrm{p}=0.04(\mathrm{~S})$ \\
05.87 & $74.33 \pm 11.34$ & \\
\hline
\end{tabular}

BAS (Burden Assessment Schedule);

\section{Significant (S)}

Table 7 below is showing the relationship between psychological well-being and socio-demographic factors among caregivers, identified significant negative relationship between caregivers' age and their psychological well-being (-0.51). Results also identified that there is no statistically significant difference in psychological well-being among gender groups. Caregivers having high level/status of education are experiencing better psychological wellbeing having means score of PGWB for illiterate, and graduation and post-graduation groups was $55.98 \pm$
14.21 and $76.11 \pm 11.55$ respectively, showing statistically significant differences between different educational status and levels. Results of study identified that there is no statistically significant difference between psychological well-being of rural and urban area caregivers and as per analysis of previous literature, there is no single study seek at correlation between residence (rural and urban) groups of caregivers and their psychological wellbeing. 
Table 7: Relationship between Psychological Well-Being and Socio-Demographic Factors of Caregivers

\begin{tabular}{|c|c|c|}
\hline Variables & PGWB $($ Mean \pm SD) & Significance \\
\hline \multicolumn{3}{|l|}{ Age Groups: } \\
\hline 21---30 Years & $71.78 \pm 17.18$ & $r=-0.51$ \\
\hline 31---40 Years & $69.22 \pm 15.93$ & $\mathrm{p}=0.01(\mathrm{~S})$ \\
\hline 41---50 Years & $49.21 \pm 15.11$ & \\
\hline 51 years and Above & $49.15 \pm 18.33$ & \\
\hline \multicolumn{3}{|l|}{ Gender Groups: } \\
\hline Males & $61.36 \pm 16.09$ & $\mathrm{t}=0.354$ \\
\hline Females & $53.19 \pm 19.21$ & $\mathrm{p}=0.643(\mathrm{NS})$ \\
\hline \multicolumn{3}{|l|}{ Educational Status } \\
\hline Illiterate Person & $55.98 \pm 14.21$ & $\mathrm{p}=0.005(\mathrm{~S})$ \\
\hline Primary Level & $56.33 \pm 15.04$ & \\
\hline Middle Level & $67.78 \pm 15.90$ & \\
\hline Secondary Level & $79.19 \pm 09.53$ & \\
\hline Graduation and Post-Graduation & $76.11 \pm 11.55$ & \\
\hline \multicolumn{3}{|l|}{ Residential Area/Location } \\
\hline Rural Residential Area/Location & $58.22 \pm 15.13$ & $\mathrm{t}=1.324$ \\
\hline Urban Residential Area/Location & $67.19 \pm 17.02$ & $\mathrm{p}=0.214(\mathrm{NS})$ \\
\hline
\end{tabular}

(PGWB) Psychological General Well-Being Index;

\section{NS for "Not Significant" and S for Significant}

Table 8 below is showing the categorization of psychological well-being of caregivers on basis of their relationship with patients and identified that siblings are enjoying highest well-being while spouses are experiencing least psychological wellbeing. Also, there is negative statistically

Table 8: Relationship between PGWB Index, based on Relations of Caregivers and Years (Duration of Care)

insignificant relationship between psychological well-being and duration of care $(r=-0.17, p<0.24)$ while there is significant negative relationship between psychological well-being and burden and distress felt by the caregivers $(r=-0.81)$.

\begin{tabular}{lll}
\hline Variables & PGWB (Mean \pm SD) & Significance \\
\hline Relationship & $57.63 \pm 11.99$ & \\
Parents (Father/Mother) & $49.72 \pm 14.47$ & $\mathrm{p}<0.002(\mathrm{~S})$ \\
Spouses (Husband/Wife) & $71.89 \pm 16.43$ & \\
Siblings (Sister/Brother) & $69.22 \pm 14.39$ & \\
Others (Daughter/Son) & & $\mathrm{r}=-0.17, \mathrm{p}=$ \\
& $74.33 \pm 11.34$ & $0.26(\mathrm{NS})$ \\
\hline
\end{tabular}


PGWBI (Psychological General Well-Being Index); NS for "Not Significant" and S for Significant

\section{Discussion}

Results of study identified that most of the patients were having low educational status and were males, about $3 / 4$ were residing in rural areas and were unemployed mainly, indicating the functional and occupational impairment among patients due to the mental chronic illness i.e. the schizophrenia. Similarly, majority of the caregivers were from male gender group and were employed. On the average they were caring for patients for 5 to 6 years, showing that these caregivers were long-term care providers and were stable. Results of study have shown that caregiving has had significant impact on health of caregivers, and as reported by the caregivers they usually spent less time on their own health as they have had increased involvement in caregiving for patients. Different studies ${ }^{22,23,24}$ have reported that caregiving to patients has adverse impacts on the mental and physical health of caregivers, both in context of subcontinent and Western context ${ }^{25,26,27}$.

Study identified the significant positive relationship between level of distress/burden that caregivers experienced and their age, implying that the burden level increased with the increased age of caregivers and these findings are consistent with findings of Juvang et al. ${ }^{29}$ and Rammohan et al. ${ }^{30}$ It is also identified that with increased age of caregivers, they are more worried for patients' care specifically for future care. Older caregivers are unable to provide good care to patients and these findings are consistent with findings of Roychaudhuri ${ }^{23}$ and Martyn ${ }^{31}$ in which younger age groups experienced more burden. Contrary to the results of this study, Nehra et al. ${ }^{32}$ identified that female caregivers are experiencing more burden and Juvang 29 identified negative relationship between level of education of caregivers and burden they experienced.

It is also identified that there is no significant relationship between residential setting and burden families are experiencing and these findings are consistent with findings of Ali and Bhutti ${ }^{34}$ while these findings and results are inconsistent with Ranga ${ }^{35}$, showing that urban caregivers have greater burden as compared with rural caregivers. Additionally, spouses are found experiencing more burden than the parents which are similar to Rammohan et al. ${ }^{30}$ and other studies including Juvang et al. ${ }^{29}$, Kumar et al., ${ }^{36}$, Vahora et al., ${ }^{36}$, and study identified strong positive correlation between time given by the caregivers and burden faced by them. Finally, old age caregivers were found experiencing poor psychological well-being and experiencing more burden.

These findings are contrary with the findings of Magria et al. ${ }^{38}$, reported that younger caregivers are experiencing high level of distress and burden. Marimuthu et al., ${ }^{24}$ in contrast to the findings of this study identified that about 53 percent of caregivers experienced psychiatric issues and problems were female caregivers while Shanker et al., ${ }^{40}$ identified that the global disability is found higher among the females and caregivers with the lower level of education are more correlated with the psychiatric problems. These findings are differently identified by the Chaturedi ${ }^{40}$, identified that the distress and 
burden is found higher among caregivers with higher educational status. Caregiver parents are experienced more well-being as compared with the spouses but

\section{Conclusion:}

Study has identified that about 80 percent of caregivers reported that they experienced moderate level distress and burden while old age caregivers are experiencing the higher distress/burden while educational status and gender have no significant relationship and effect on the level of distress and burden. Spouses are experiencing significantly higher burden which is significantly positively correlated with the duration in years for which care is provided. It is identified that psychological well-being is relatively lower among the old age caregivers as well as among those having low level of education. Siblings experienced relatively greater level of wellbeing while spouses have less score of psychological well-being.

It is also identified during course of this study that there is significant negative correlation between still less than the siblings while some of the studies have identified that spouses are experiencing more psychological well-being ${ }^{30}$.

psychological well-being and the burden/distress experienced therefore there if the caregivers are facing/experiencing higher burden level would have less psychological well-being. One among different limitation of subject study was that it is carried out in hospital which was located in urban territory therefore results would not be generalized for the large size population. Secondly, the sample size taken was small, therefore study with larger size of sample would be conducted in future. Finally, the care given to the patients of schizophrenia is depending on the caregiving by the primary caregivers, therefore it is essential to plan for interventions, reducing their burden and caregiving distress on primary caregivers in order to improve their psychological well-being. 


\section{References:}

1. Ali M, Bhatti RS. Social support system and family burden due to chronic schizophrenia in rural and urban background. Indian J Psychiatry 1988;30:349-53.

2. Chakrabarti S, Raj L, Kulhara P, Avasthi A, Verma SK. Comparison of the extent and pattern of family burden in affective disorders and schizophrenia. Indian J Psychiatry 1995;37: 105-12.

3. Chen HM, Huang MF, Yeh YC, Huang WH, Chen CS. Effectiveness of coping strategies intervention on caregiver burden among caregivers of elderly patients with dementia. Psychogeriatrics. 2015;15(1):20-5.

4. Cohler BJ, Pickett SA, Cook JA. The psychiatric patient grows older: issues in family care. In: Aging and Caregiving, Liebowitz B, Light E (Eds). New York: Springer, 1991.

5. Desai M. Families with problems in India: recommendations for policies, intervention, teaching and research In: Unit for Family Studies (Ed), Research on Families with Problems in India, Vol. 1, Bombay: TISS, 1991.

6. Folkman S, Lazarus RS, Dunkel-Schetter C, DeLongis A, Gruen RJ. Dynamics of a stressful encounter: cognitive appraisal coping, and encounter outcomes. J Pers Soc Psychol. 1986; 50(5):992-1003.

7. Gopinath PS, Chaturvedi SK. Distressing behaviour of schizophrenics at home. Acta Psychiatr Scand 1992;86:185-8.

8. Hinrichsen G, Lieberman JA. Family attributions and coping in the prediction of emotional adjustment in family members of patients with schizophrenia. Acta Psychiatr Scand 1999;100: 359-66.
9. Hoenig J, Hamilton MW. The schizophrenic patient in the community and his effect in the household. Int J Soc Psychiatry 1966;12:165-76.

10. Hsiao CY, Riper MV. Individual and family adaptation in Taiwanese families of individuals with severe and persistent mental illness (SPMI). Res Nurs Health. 2009;32(3):307-20.

11. Jayakumar C, Jagadheesan K, Verma AN. Caregiver's burden: a comparison between obsessive compulsive disorder and schizophrenia. India J Psychiatry 2002;44:33742.

12. Juvang L, Lambert CE, Lambert VA. Predictors of family caregiver's burden and quality of life when providing care for a family member with schizophrenia in the People's Republic of China. Nurs Health Sci 2007;9:192-8.

13. Kuipers E, Paul E, Bebbington PE. Research on burden and coping strategies in families of people with mental disorders: problems and perspectives. In: Families and Mental Disorders: From Burden to Empowerment, Sartorius N, Leff J, Lopez Ibor JJ, Okasha A (Eds). Chichester, UK: John Wiley, 2005. pp. 217-34.

14. Kumar S, Mohanty S, Kumar A. Perceived burden of care as a function of diagnosis and gender. Indian J Psychiatry 2002;44 (Suppl):54.

15. Lazarus R, Folkman S. Stress Appraisal and Coping. New York: Springer, 1984. pp. 334356.

16. Lefley HP. Aging parents as caregivers of mentally ill adult children: an emerging social problem. Hosp Commun Psychiatry 1987;38:1063-70. 
17. Lefley HP. Family burden and family stigma in major mental illness. Am Psychol 1989;44:55660.

18. MadianosM, EconomouM, Dafni O, KoukiaE, Palli A, Rogakou E. Familial disruption, economic hardship and psychological distress in schizophrenia: can they be measured? Eur Psychiatry 2004; 19:408-14.

19. Magana S, Garcia J, Hernandez M, Cortez R. Psychological distress among Latino family caregivers of adults with schizophrenia: the roles of burden and stigma. Psychiatr Serv 2007; 58:378-84.

20. Marimuthu C, Prashanth NR, John JK, Russell P. Mental health of primary caregivers. Indian $\mathbf{J}$ Psychiatry 2000;42:46.

21. Marnocha S, Marnocha M. How older female spouses cope with partners' coronary artery bypass graft surgery. Nurs Res Pract. [Internet]. 2013 [Access 16 Dec 2015];2013. Article 923137. 7 pages. Available from: http://dx.doi.org/10.1155/2013/923137

22. Martens L, Addington J. The psychological well-being of family members of individuals with schizophrenia. Soc Psychiatry Psychiatr Epidemiol 2001;36(3):128-31.

23. Martyns-Yellowe IS. The burden of schizophrenia on the family: a study from Nigeria. Br J Med Psychol 1992;161:779-82.

24. McCleery A, Addington J, Addington D. Family assessment in early psychosis. Psychiatry Res 2007;152(2-3):95-102.

25. Nehra R, Chahrabarti S, Kulhara P, Sharma R. Family burden and its correlates among caregivers of schizophrenia and bipolar affective disorder. J Mental Health Hum Behav 2006;11:78-84.
26. Nunley M. The involvement of family in Indian psychiatry. Cult Med Psychiatry 1998;22:31753.

27. Oldridge ML, Hughes ICT. Psychological wellbeing in families with a member suffering from schizophrenia: an investigation into longstanding problems. $\mathrm{Br} \quad \mathrm{J}$ Psychiatry 1992;161:249-51.

28. Pai S, Kapur RL. The burden on the family of a psychiatric patient: development of an interview schedule. Br J Psychiatry 1981;138:332-5.

29. Platt S. Measuring the burden of psychiatric illness on the family: an evaluation of someratingscales. Psychol Med1985;15:383-93.

30. Provencher HL,Fournier JP, Perreault M, VezinaJ. The caregiver's perception of behavioral disturbance inrelatives with schizophrenia: a stress coping approach. Commun Ment Health J 2000;36: 293-306.

31. Rammohan A, Rao K, Subbakrishna DK. Burden and coping in caregivers of persons with schizophrenia. Indian J Psychiatry 2002;44:2207.

32. Ranga Rao NVSS. Comparative Study of Disability and Family Burden in Rural and Urban areas. MD Thesis, Bangalore University, Bangalore, 1988.

33. Roychaudhuri J, Mondal D, Boral A, Bhattacharya A. Family burden among long term psychiatric patients. Indian J Psychiatry 1995;37:81-5.

34. Salleh MR. The burden of care in schizophrenia in Malay families. Acta Psychiatr Scand 1994;89:180-5.

35. Schene AH, Tessler RC, Gamache GM. Caregiving in severe mental illness: conceptualization and measurement. In: Mental 
Health Service Evaluation, Knudsen HC, Thornicroft G (Eds). UK: Cambridge University Press, 1996. . pp. 296-316.

36. Schene AH, Van Wijngaarden B, Koeter MWJ. Family caregiving in schizophrenia: domains and distress. Schizophr Bull 1998;24:609-18.

37. Schene AH. Objective and subjective dimensions of family burden: towards an integrative framework for research. Soc Psychiatry Psychiatr Epidemiol 1990;25:289-97.

38. Shankar R, Kamath S, Joseph A. Gender differences in disability: a comparison of married patients with schizophrenia. Schizophr Res 1995;6:17-23.

39. Smith ME, Lindsey MA, Williams CD, Medoff DR, Lucksted A, Fang LJ, et al. Race-Related Differences in the Experiences of Family Members of Persons with Mental Illness Participating in the NAMI Family to Family Education Program. Am J Commun Psychol. 2014;54:316-327.

40. Van Wijingaarden, Schene AH, Koeter MWJ. Caregiving consequences in the Netherland and other European countries: the development and use of the Involvement Questionnaire. In:FamilyInterventionsin

Mentallllness:InternationalPerspectives, Lefley HP, Johnson DL (Eds). Westport, CA: Praeger Publishers; 2002.

41. Varghese A, Khakha DC, Chadda RK. Pattern and Type of Aggressive Behavior in Patients with Severe Mental Illness as Perceived by the Caregivers and the Coping Strategies Used by Them in a Tertiary Care Hospital. Arch Psychiatr Nurs. 2016;30(1):62-9.
42. Vohra AK, Garg S, Gaur DR. A study of burden on families of schizophrenia and depressive disorder. Indian J Psychiatry 2000;42(Supp):33.

43. Wahl OF, Harman CR. Family views of stigma. Schizophr Bull 1989;15:131-9.

44. Winefield HR, Harvey EJ. Needs of family caregivers in chronic schizophrenia. Schizophr Bull 1994;20:557-66. 